\title{
Jean-Pierre Ollivier, Proust et les sciences
}

\section{Chiara Nifosi}

\section{(2) OpenEdition \\ Journals}

\section{Edizione digitale}

URL: https://journals.openedition.org/studifrancesi/21617

DOI: 10.4000/studifrancesi.21617

ISSN: 2421-5856

\section{Editore}

Rosenberg \& Sellier

\section{Edizione cartacea}

Data di pubblicazione: 1 décembre 2019

Paginazione: 603

ISSN: 0039-2944

\section{Notizia bibliografica digitale}

Chiara Nifosi, «Jean-Pierre Ollivier, Proust et les sciences», Studi Francesi [Online], 189 (LXIII | III) | 2019, online dal 01 mars 2020, consultato il 11 novembre 2021. URL: http://journals.openedition.org/ studifrancesi/21617 ; DOI: https://doi.org/10.4000/studifrancesi.21617

Questo documento è stato generato automaticamente il 11 novembre 2021.

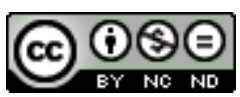

Studi Francesi è distribuita con Licenza Creative Commons Attribuzione - Non commerciale - Non opere derivate 4.0 Internazionale. 


\title{
Jean-Pierre Ollivier, Proust et les sciences
}

\author{
Chiara Nifosi
}

\section{NOTIZIA}

Jean-Pierre Ollivier, Proust et les sciences, Paris, Honoré Champion, 2018, 226 pp.

1 Questa volta è un professore di medicina ad avvicinare con estrema competenza e dedizione il testo proustiano, per evidenziarne ancora una volta la spiccata vocazione interdisciplinare. Nel presente volume, infatti, Jean-Pierre ollivier prende in esame il discorso scientifico all'interno della Recherche, a partire da tre domande fondamentali relative alla sua ragion d'essere, alla sua pertinenza e alla sua funzione nel tessuto narrativo del romanzo («Introduction», p. 14).

2 Il saggio, organizzato in dieci capitoli, si interroga innanzitutto sulle conoscenze a disposizione dell'autore, tracciando un resoconto dei progressi nell'ambito della fisica negli anni precedenti alla redazione dell'opera; in seguito Ollivier rintraccia le possibili fonti a cui Proust avrebbe attinto per sviluppare riferimenti così precisi ad un sapere scientifico oggettivamente vasto: il professore Adrien Proust, padre di Marcel, sarebbe stato per quest'ultimo il primo portavoce del positivismo di Comte e dello scientismo di Berthelot (p. 18), mentre il contatto con una più ampia divulgazione scientifica si dovrebbe tanto alla frequentazione dei salons (pp. 19-24) quanto alla circolazione delle più recenti teorie nelle riviste dell'epoca (pp. 24-25). Nel secondo capitolo, Ollivier avanza l'ipotesi per cui le scienze avrebbero offerto a Proust una prima e cruciale porta d'accesso a una realtà che il progresso scientifico inizia a presentare come controintuitiva, di difficile rappresentazione (p. 28); lo dimostra ad esempio la scomposizione sempre più complessa della materia. Per ollivier, le scienze entrano di diritto nel processo di creazione letteraria; egli propone così di considerare la Recherche come un modello di coabitazione di due forme di conoscenza apparentemente inconciliabili l'empirismo scientifico che emana dalla prosa proustiana da un lato, l'espressione di 
una soggettività sotto forma di impressione dall'altro. La ragione profonda di tale coabitazione è spiegata nel capitolo terzo, in cui l'A. analizza il ruolo cardine della metafora: se consideriamo la Recherche come una "dimostrazione" per analogia sulla natura del Tempo (termine, quello virgolettato, utilizzato più volte da Proust), il suo linguaggio dovrà ricorrere a ogni strumento concettuale utile a tal fine, compresi gli strumenti afferenti ai più svariati campi del sapere scientifico (p. 39).

3 Nei capitoli seguenti, Ollivier passa in rassegna una serie di concetti di natura scientifica presenti nel romanzo, la cui rilevanza è valutata in base al numero di occorrenze testuali: vengono così analizzati il ricorso proustiano alle «leggi» (capitolo 4), la natura della realtà nella Recherche (capitolo 5), il rilievo delle scoperte ottiche (capitolo 7), le nozioni di mondo e universo (capitolo 8), e la presenza della geometria, soprattutto nell'ambito della costruzione spaziale attraverso le sezioni coniche (capitolo 9). Una menzione a parte merita il capitolo di confronto tra Proust e Einstein (capitolo 6): se, da un lato, entrambi descrivono un Tempo alternativo al tempo segnato dagli orologi (p. 83), è altrettanto vero che, dall'altro, l'autore della Recherche non ha avuto realmente occasione di beneficiare della Teoria della Relatività; certo è che dall'accostamento ad Einstein, soprattutto negli ultimi anni della sua vita, la sua reputazione ha tratto giovamento (p. 94). Nel capitolo 10, Ollivier si sofferma sulle questioni di eredità e genetica, le quali sono messe direttamente in dialogo con il più ampio discorso sulla memoria: in quanto forma biologica della permanenza, la trasmissione del patrimonio genetico serba memoria del vivente, così come l'arte garantisce la trasmissione della memoria individuale in un perfetto continuum (p. 202).

4 La Recherche, in quanto celebrazione della vita (p. 206), risulta essere per Ollivier l'esempio più straordinario di integrazione del discorso scientifico in quello propriamente poetico, in quanto le scienze forniscono il trampolino ideale di una vera $\mathrm{e}$ propria metafisica prendendo parte a un'esplorazione totale del vivente. 